\title{
CONSUMO POLÍTICO SUSTENTÁVEL EM CONTEXTO ABISSAL
}

Douglas Augusto Carneiro Neves

Graduando em Ciências da Religião na Universidade Estadual do Pará (UEPA).Possui experiência em Antropologia. E-mail: dougneves2018@gmail.com

\section{RESUMO}

O artigo propõe uma reflexão, partindo da análise dos saberes locais, produzidos por pessoas em contato com o meio ambiente em seu habitus(Bourdieu), expressando esses saberes locais no tratamento dos canudos plásticos, e que são invisibilizados por campanhas publicitárias que ignoram ou não têm conhecimento de tais saberes, produzindo assim, uma pressão social entorno desses saberes locais . O artigo objetiva a construção de sujeitos consumidores, políticos e sustentáveis, através do confronto dos saberes locais com as campanhas de consumo sustentáveis, procurando sempre a reflexão por parte dos participantes da pesquisa com o intuito de transparecer esses saberes locais em detrimento das campanhas publicitárias. O resultado da pesquisa culmina com a proposta para a criação e construção de consumidores políticos sustentáveis, onde culmina no que chamamos ao longo do artigo de epistemologias do sul, lugar onde os saberes locais entram em diálogo com a pressão que as campanhas publicitárias exercem sobre eles, ressignificando ao seu modo o tratamento do uso de canudos plásticos em seu cotidiano.

PALAVRAS-CHAVE: Sustentabilidade; Consumo; Habitus; Epistemologias do Sul.

\section{SUSTAINABLE POLITICAL CONSUMPTION IN ABYSSAL CONTEXT}

\begin{abstract}
The article proposes a reflection, starting from the analysis of local knowledge, produced by people in contact with the environment in their habitus (Bourdieu), expressing this local knowledge in the treatment of plastic straws, which are invisible by advertising campaigns that ignore or not. are aware of such
\end{abstract}


knowledge, thus producing social pressure around this local knowledge. The article aims at the construction of consumer, political and sustainable subjects through the confrontation of local knowledge with sustainable consumer campaigns, always seeking the reflection of the research participants in order to show this local knowledge to the detriment of advertising campaigns. The result of the research culminates in the proposal for the creation and construction of sustainable political consumers, where it culminates in what we call throughout the article Southern Epistemologies, a place where local knowledge comes into dialogue with the pressure that advertising campaigns exert on them. , resignifying in its own way the treatment of the use of plastic straws in its daily life.

KEYWORDS: Sustainability; Consumption; Habitus; Southern Epistemologies.

\section{INTRODUÇÃO}

O presente artigo irá deter-se em analisar os saberes locais, que " existem incorporados em práticas sociais (Boaventura, pg.20), em conjunto com as suas noções de meio ambiente e de natureza, e como esses dois aspectos se manifestam no uso e no tratamento dos canudos plásticos, pensando o consumo de canudos plásticos como uma campanha de consumo sustentável que se impõe sob os saberes locais, invisibilizando de alguma forma os modos que os saberes reagem a essas campanhas. O objetivo da pesquisa é analisar como esses saberes locais (" conhecimentos ' inexistentes', assim considerados pelo fato de não serem produzidos de acordo com metodologias aceitáveis", SANTOS pg. 20) se impõe a essas campanhas oriundas "de fora", ressignificando a seu modo o consumo sustentável de canudos plásticos, ou seja, nas palavras de SANTOS: " transformar sujeitos presentes como condição imprescindível para identificar e validar conhecimentos que podem contribuir para a emancipação e a libertação sociais" pg. 19. Utilizando o método quantitativo, feita a partir da aplicação de questionário, observou-se a partir da resposta oral descrita pelos participantes da pesquisa e captando seus saberes em contexto de diálogo, como nos refere Boaventura(2019): "aquilo que circula na conversa é muitíssimo mais do que aquilo que é dito" pg. 269. Os resultados da pesquisa indicaram que os saberes locais de alguma forma são afetados por correntes oriundas "de fora", tornando invisibilizadas as pessoas que tratam esses canudos no cotidiano. Porém, os saberes locais impõem-se também de alguma forma à essas campanhas, tratando de modificá-las a seu modo e produzindo o que hoje chamamos de consumo político sustentável.

Os saberes locais, que Boaventura de Sousa Santos esclarece a nós como 
“conhecimentos 'inexistentes', assim considerados pelo fato de não serem produzidos de acordo com metodologias aceitáveis"(2019,pg. 20) e que são adquiridos por meio de dois pilares fundamentais, que são o habitus(conceito fundamentado por Bourdieu, e que explica a relação entre indivíduo e sociedade e como isto ocorre), e meio ambiente( a interrelação entre os aspectos físicos, químicos e biológicos e os aspectos sociais, culturais e políticos) e que se manifestam na relação com o consumo e tratamento dos canudos plásticos, assim como na percepção de olhares no uso e consumo desses mesmos objetos são afetados por essas campanhas, porém, os saberes locais também reagem e ressignificam a seu modo às campanhas publicitárias oriundas "de fora", como nos mostra Bourdieu(1963) em seu conceito de habitus.

As campanhas publicitárias, muitas vezes associadas à noção de sustentabilidade pautada na percepção ecológico preservacionista, onde há a separação cartesiana entre indivíduo, seu meio social e o meio ambiente, dotado de aspectos físico-químicos, não põem em questão o fato de que os indivíduos e os grupos sociais diversos entre si reagem de uma determinada forma a essas campanhas, todas com suas particularidades. Por isso, o projeto de ideia das campanhas publicitárias têm dois defeitos ou lacunas: serem pautadas na separação entre o social e o meio ambiente, ou seja, a não consideração da integração e da percepção que o meio social adquire ao lidar com os objetos físico-químicos, e que por isso leva-nos à segunda lacuna, que seria a invisibilidade de como esses meios sociais lidam com esses objetos, expressas nas campanhas publicitárias. Esses dois aspectos criam uma pressão social por meio das campanhas publicitárias, no qual se percebe uma pressão por meio da sociedade por não enxergar como esses saberes reagem a essas campanhas, virando uma pressão social em termos de sociabilidade, no que tange ao capital simbólico (Bourdieu 1983).

Articulando o conceito de habitus de Bourdieu, em que explicita a não separação entre indivíduo e sociedade, e que são conectados pelo que Bourdieu chama de capital simbólico, o poder que ou a sociedade, ou o indivíduo tem pressão ou domínio sobre o outro em determinada situação de sociabilidade com o de epistemologias do sul de Boaventura de Sousa Santos, no qual o diálogo que indivíduo ou o grupo social no qual o indivíduo faz parte trava com a sociedade hegemônica, no caso as campanhas publicitárias, resultaria em um novo tipo de ressignificação do mundo, no qual os indivíduos e os grupos sociais reinterpretariam o mundo proposto pela sociedade hegemônica a seu modo, dando novo significado a determinadas práticas sociais, que são interdependentes do seu meio ambiente no qual fazem 
parte, tratando de forma nova e diferente, porém, mais a seu modo do que pelo proposto pela sociedade hegemônica, atenuando ou ainda eliminando em determinados momentos as hierarquias existentes entre a sociedade e os grupos sociais invisibilizados, o que Boaventura chama de abissal, que seria justamente a hierarquia existente entre esses dois tipos.

\section{DISCUSSÃO DE CONCEITOS: HABITUS, CAMPANHAS PUBLICITÁRIAS ALIADAS AO CONCEITO DE MEIO AMBIENTE ECOLÓGICO PRESERVACIONISTA E EPISTEMOLOGIAS DO SUL}

Bourdieu explica-nos, em seu conceito de habitus, que na verdade, não existe uma separação entre indivíduo e sociedade, tal como proposto por Durkheim, e que essa separação é orientada à modo de o indivíduo não saber que mecanismos fazem ele se relacionar com a tão distante sociedade. Bourdieu propõe essa explicação, dize-nos que o habitus é " um sistema de disposições duráveis e transponíveis que, integrando todas as experiências passadas, funciona a cada momento como uma matriz de percepções, e torna possível a realização de tarefas infinitamente diferenciadas, graças às transferências analógicas de esquemas"(Bourdieu,1983, p.65). Ou seja, um princípio de correspondência entre as práticas individuais e as condições de existência Bourdieu (1963). E que são aplicadas em situações particulares com uma certa dose de invenção e criatividade. Ele realiza sem cessar um ajustamento ao mundo que só excepcionalmente assume a forma de uma conversão radical" (1983, p.106). Portanto, há mecanismos, que Bourdieu os chama de matriz de percepções que o indivíduo adquire em suas experiências passadas e que se submetem à reformulações ao momento em que é submetido às condições de sociabilidade existentes.

Para elucida-lo à nossa pesquisa, iremos atribuir às campanhas publicitárias como sendo a sociedade e os saberes locais como o indivíduo, fazendo apenas uma analogia. Ou seja, aos olhos de Durkheim, as campanhas publicitárias exercem pressão sobre os saberes locais de modo que os mesmo não têm a opção de se sobrepor a essas ditas cujas, e que são suprimidas ao ponto de não obter o poder necessário a se contrapor à essas campanhas. Na visão de Bourdieu, existe uma correlação entre os saberes locais e as campanhas publicitárias, na medida em que os saberes locais adquirem o que Bourdieu chama de capital simbólico. E é justamente esse capital simbólico que chamamos de epistemologias do sul, ou seja, o reajustamento do mundo a seu modo, capaz de re-simbolizar as práticas sociais que as campanhas publicitárias impõe sobre os saberes locais, de modo a produzir novas práticas 
sociais e uma nova visão e por isso mesmo uma nova prática política capaz de fazer frente à essas campanhas publicitárias e as práticas à ela submetidas.

As campanhas publicitárias que propõe consumos sustentáveis são feitas através de pesquisas de determinados grupos sociais, tendo como referência esses grupos sociais( que não são excluídos aqui), de determinado local e tempo. Porém, essas mesmas pesquisas são termináveis, no que tange à não análise de todos os grupos variáveis e que são invisibilizados as suas práticas em detrimento das práticas analisadas nas pesquisas feitas para as campanhas publicitárias.

Aliado a recursos tecnológicos e à noção ecológico preservacionistas, as campanhas publicitárias funcionam da seguinte forma: são espalhados em vários grupos sociais distintos, na televisão e na internet por exemplo, tendo como amostra um determinado grupo social, acaba impondo à outros grupos sociais não analisados que não falam por si só mas que são falados por essas campanhas e grupos sociais, provocando uma pressão social em cima deles, tornando invisibilizados as práticas e saberes locais que esses determinados grupos não analisados exercem em seu habitus, que seria a interrelação entre a sociedade e esses grupos sociais.

Porém, o problema é a invisibilização, mesmo que os grupos sociais não analisados tenham alguma relação entre esses grupos sociais analisados e as campanhas publicitárias, esses mesmos grupos não têm a opção de falar por si só e elaborar e ressignificar as práticas sociais ditas por esses grupos sociais analisados expressos nas campanhas publicitárias, ficando por isso mesmo oprimidos por esses dois agentes.

A metodologia pós-abissal(SANTOS,2019), justamente está aí para ressignificar levando em conta todos os agentes envolvidos, tanto as práticas que as campanhas publicitárias impõe expressas levando em conta a análise de determinados grupos sociais, ou seja, propor uma reflexão para os participantes da pesquisa através do questionário, em consonância com os seus saberes locais uma ressignificação a seu modo sobre a opinião deles sobre isso e justamente reinventar as suas práticas sociais no tratamento dos canudos plásticos.

\section{METODOLOGIA APLICADA}

O procedimento metodológico utilizou-se o questionário para fazer a intermediação entre o pesquisador, os participantes da pesquisa (dotado de saberes locais, adquiridos por meio de seus habitus e meio ambiente), e as campanhas publicitárias (que exercem pressão 
social sobre os indivíduos dotados de saberes próprios, locais).

Durante a entrevista, foram selecionadas perguntas de cunho a saber o perfil dos participantes como a noção de meio ambiente, idade e local de atuação profissional. Logo mais, foram selecionadas perguntas que corresponderiam ao tratamento e às percepções ao uso de canudos plásticos pelos participantes e grupos sociais no qual participam. Percebeu-se uma pressão social ao nos referirmos à essas perguntas e que afetaram diretamente às práticas sociais quanto ao uso dos canudos e que trataram de defender o seu ponto de vista ao uso e tratamento dos referidos objetos.

E que por isso, ao defrontarem-se tanto com as perguntas, quanto com o pesquisador observou-se o confronto também com essas campanhas publicitárias, no qual percebeu-se uma ressignificação por parte dos participantes dessa pesquisa ao diálogo com o pesquisador. Como nos esclarece Boaventura de Sousa Santos: " aquilo que circula na conversa é muitíssimo mais importante do que aquilo que é dito"(2019, pg. 19), ao que cria o que SANTOS(2019) chama de epistemologias do sul, ou seja, as "noções de meio ambiente e tratamento no uso de canudos plásticos nos seus próprios termos e condições”.

O que tentamos fazer ao aplicar o questionário, confrontando os saberes locais com as perguntas, estimulou os participantes a entrar em diálogo com as campanhas publicitárias como nos mostra SANTOS(2019):"Entrevistar e leva-los a formular as suas ideias da melhor forma possível, confrontando-os com questões e situações que testemunham a natureza reflexiva, crítica e criativa do seu pensamento" pg.273. "Uma vez que sou um dos interlocutores, o meu próprio conhecimento escrito é submetido a oralização e, desse modo, as transformações que o conhecimento meu interlocutor ou da minha interlocutora sofre são paralelas às do meu próprio conhecimento”(SANTOS,2019,pg. 270).

\section{CONSIDERAÇÕES FINAIS}

A articulação entre as epistemologias do sul (construídas em diálogo com a noção de habitus de Pierre Bourdieu) em consonância com as noções de meio ambiente e natureza em diálogo e confronto com a pressão das campanhas publicitárias de consumo sustentável por meio das entrevistas irá obter o que chamamos de consumo político sustentável. Ou seja, a ressignificação dos objetos( no caso os canudos plásticos) de modo a lidar com eles de modo autônomo e a seu modo.

O intuito da pesquisa não é somente extrair dados com o intuito de leva-las a um dito 
laboratório, explica-las posteriormente através da teoria e somente depois propor uma aplicação através de projetos e de políticas públicas, isso também é válido na pesquisa. Mas também propor a reflexão e ao mesmo o questionamento por parte dos participantes da pesquisa ao contato com os desenvolvedores de campanhas publicitárias pelo intermédio do questionário e do pesquisador, propondo questões dirigidas aos participantes de modo a formularem o seu próprio questionamento em conjunto com seus saberes locais. E são essas expressões do participante da pesquisa em conjunto com o pesquisador e com as campanhas publicitárias que irão construir durante o processo de reflexão do participante que tanto o pesquisador quanto participante irão se beneficiar, no momento exato da pesquisa.

\section{REFERÊNCIAS BIBLIOGRÁFICAS}

CASTRO, Carlos Potiara. Uma perspectiva Latino-Americana sobre os estudos amazônicos. (org.) FERREIRA, Leila da Costa. In: A questão Ambiental na América Latina: teoria social e interdisciplinaridade. Campinas, SP; Editora da Unicamp,2011.

FERREIRA, Leila da Costa. Questão Ambiental na América Latina: teoria social e interdisciplinaridade. (org.) FERREIRA, Leila da Costa. In :A questão ambiental na América Latina: teoria social e interdisciplinaridade. Campinas, SP: Editora da Unicamp, 2011.

HOEFFEL, João Luiz de Moraes; REIS, Jussara Christina. O contexto de Sustentabilidade na Teoria Social
Latino-Americano: uma análise preliminar. (org.) FERREIRA, Leila da Costa. In: A questão Ambiental na América Latina: teoria social e interdisciplinaridade. Campinas, SP: Editora da Unicamp,2001.

SANTOS, Boaventura de Sousa. Belo Horizonte: Autêntica Editora, 2019.

SETTON, Maria da Graça. A teoria do habitus em Pierre Bourdieu: uma leitura contemporânea. Universidade de São Paulo, Faculdade de Educação: 2003.

SILVA, Marilena Loureiro. A educação ambiental no ensino superior brasileiro: do panorama nacional às concepções de alunos(as) de pedagogia na Amazônia. Revista eletrônica do Mestrado em Educação Ambiental.

NEVES, D. A. C. Consumo Político Sustentável Em Contexto Abissal. Complexitas - Rev. Fil. Tem. Belém, v. 4, n. 2, p. 33-39, jul./dec. 2019. Disponível em: http://www.periodicos.ufpa.br/index.php/complexitas/article/view/8053>. Acesso em: 30 de janeiro de 2020. 